\title{
Cardiovascular Disease Risk and Health-Related Quality of Life among People with Serious Mental Illness in Supportive Housing
}

\author{
Ana Stefancic \\ Columbia University https://orcid.org/0000-0002-1573-1565 \\ Nathaniel Lu \\ Zucker Hillside Hospital \\ Xiaoyan Wang \\ Washington University in Saint Louis \\ Lauren Bochicchio \\ Columbia University \\ Christopher Weatherly \\ Washington University in Saint Louis \\ Kimberly Roth \\ Washington University in Saint Louis \\ Leopoldo J Cabassa ( $\square$ ljcabassa@wustl.edu ) \\ Washington University https://orcid.org/0000-0002-1872-4141
}

\section{Research article}

Keywords: cardiovascular disease risk, quality of life, serious mental illness, racial/ethnic minorities, supportive housing

Posted Date: August 12th, 2020

DOI: https://doi.org/10.21203/rs.3.rs-39495/v1

License: () (1) This work is licensed under a Creative Commons Attribution 4.0 International License. Read Full License 


\section{Abstract}

Background: Given indications of widening disparities in mortality for people with serious mental illness, understanding and reducing their risk of cardiovascular disease (CVD) and improving health-related quality of life is an urgent public health priority. This study examined CVD risk factor clustering, health-related quality of life (HRQoL), and their correlates among people with SMI who were overweight/obese (i.e., BMI $\geq 25$ ) and living in supportive housing.

Methods: Baseline data were used from participants enrolled in a clinical trial examining the effectiveness of a peer-led healthy lifestyle program. univariate analyses were used to describe the distribution of individual risk factors and the cumulative number of CVD risk factors. Bivariate and regression analyses were used to explore correlates of individual CVD risk factors, the cumulative number of risk factors, and HRQoL Physical and Mental Health Composite Scores.

Results: Participants were 48.7 years old, on average $(s d=11.6)$ and the majority identified as male $(57.3 \%)$ and as racial/ethnic minorities (82\%; primarily non-Hispanic black). Most participants (75.4\%) had at least two co-occurring CVD risk factors and almost half (46.7\%) had three or more, most commonly obesity, smoking, and hypertension. Prevalence of individual risk factors, particularly smoking and diabetes, varied by demographic and clinical characteristics. Identifying as female, older age, and taking second generation antipsychotic medication were associated with having more co-occurring CVD risk factors, while having completed high school was associated with fewer risks. Number of co-occurring CVD risk factors, identifying as female, and greater psychiatric symptoms were negatively associated with physical HRQoL. Older age, lower psychiatric symptoms, and greater internal locus of control were positively associated with mental HRQoL.

Conclusion: Even when compared to other studies examining CVD risk among individuals diagnosed with schizophrenia, our study sample generally had higher rates of clustering of multiple risk factors, highlighting the need for urgent intervention among those living in supportive housing. Demographic and clinical factors further identify those who may have the highest risk as well as factors that may adversely affect perceived health status and functioning. Reducing CVD risk and improving HRQoL will likely require expanding access to quality care, adapting intervention approaches to subpopulations, and providing increased support to facilitate health behavior change and perceived control for modifiable risk factors.

Trial Registration: This trial was registered through ClinicalTrials.gov on June 26, 2014. The registration number is NCT02175641.

\section{Background}

Life expectancy in the U.S. has improved greatly over the last several decades, yet not all populations have benefited equally [1]. Significant health disparities persist leaving certain populations such as people living in poverty, racial/ethnic minorities, and those with serious mental illness (SMI) with an excess burden of morbidity and premature mortality [2]. People with SMI (e.g., schizophrenia, bipolar disorder) die approximately 10-25 years earlier than the general population $[3,4]$ and recent trends suggest that these health disparities are actually growing. A widening mortality gap has been documented between individuals with schizophrenia and bipolar disorder relative to the general population [5]. Strategies to help achieve health equity will require, in part, identifying groups with some of the highest vulnerabilities and addressing the multitude of challenges they face in maintaining health and wellbeing.

Similar to the general population, cardiovascular disease (CVD) is the leading cause of death among persons with SMI [6] and includes conditions such as myocardial infarction, stroke, and congestive heart failure. However, risk of developing CVD and CVDrelated mortality is greater among people with SMI [6]. A combination of factors contributes to this elevated risk, including higher rates of risky health behaviors (e.g., smoking, poor diet, sedentary lifestyle, unsafe sex), cardio-metabolic side-effects of psychotropic medications, and inadequate medical care $[6,7,8]$.

Even among persons with SMI, CVD risk can differ by subgroups, such as by race/ethnicity and history of homelessness or housing instability. Compared to non-Hispanic whites with psychiatric conditions, blacks and Hispanics with similar psychiatric conditions report higher prevalence of obesity, diabetes, and CVD [9]. For people with SMI who have experienced homelessness, vulnerabilities are further compounded due to increased exposure to communicable disease, malnutrition, violence, and victimization [10]. Such risks and exposures may partially explain estimates of 30-year CVD risk among this group as being more than twice that of population norms [11]. Further, studies of people with SMI living in supportive housing, which consists of community-based housing

Page 2/16 
coupled with a range of support services for those who have experienced homelessness/housing instability, demonstrate that this group has worse health profiles than the local population in general (e.g., higher rates of chronic disease, including hypertension, diabetes, and human immunodeficiency virus) [12].

In the general population, each CVD risk factor is independently associated with increased likelihood of CVD incidence and mortality, and the accumulation of risk factors further elevates the risk for CVD and CVD-mortality [13]. The presence of multiple, co-occurring CVD risk factors (i.e., clustering) also makes treatment more challenging and contributes to higher healthcare costs [14, 15]. Further, in non-SMI populations, clustering of CVD risk factors is associated with lower quality of life overall [16] and health-related quality of life specifically (HRQoL) [15]. HRQoL measures self-perceived health status and health-related impairment along physical, mental, and social domains [17]. HRQoL is considered a key health indicator as it is associated with adverse health outcomes, such as developing CVD and hospitalizations [18], as well as increased risk of cause-specific and all-cause mortality [19]. HRQoL also emphasizes the perceived burden of illness on daily life and is commonly used to measure the effectiveness of health interventions.

People with SMI report lower HRQoL compared to those without SMI $[20,21]$ and the presence of comorbid chronic health conditions is associated with lower perceived health and poorer functioning $[22,23]$. However, research thus far has not comprehensively explored how common CVD risk factors are collectively associated with HRQoL among persons with a broad spectrum of SMI, with prior literature primarily focusing on mood disorders or on specific indicators of CVD risk (e.g. engagement in physical activity) [24]. This is especially critical given that the negative impact of CVD risk factors on HRQoL among persons with SMI may not only be additive, but "synergistic" in that having multiple factors may contribute negatively to HRQoL over and above the impact of the sum of each individual risk [25].

Further, despite the positive impact of supportive housing on increasing housing stability and reducing use of emergency/inpatient health services, studies have often found that it is not associated with improvements in HRQoL [26, 27]. While there is a paucity of research on correlates of HRQoL in supportive housing, prior literature demonstrated that among individuals who are either homeless or formerly homeless, factors such as duration of homelessness, mental health diagnosis, perceived stress, and lower physical functioning are associated with lower HRQoL [28-30]. Given that supportive housing programs have been identified as key service settings in which to address health and quality of life for people with SMI [31], understanding clients' CVD risk profiles and the factors that may be associated with HRQoL is essential to developing more targeted health supports for this vulnerable population.

This study sought to assess the prevalence of different CVD risk factors, the extent to which they cluster, and their association with HRQoL among overweight individuals with SMI living in supportive housing. It explores this among a diverse sample with a large proportion of racial/ethnic minorities, who tend to have higher CVD risk [9]. The study also expands on existing research by moving beyond assessing CVD risk factor prevalence to also examining socio-demographic and clinical variables associated with these risk factors, as well as the relationship between the cumulative number of risk factors and HRQoL among people with SMI.

\section{Methods}

Overview. This study utilized baseline data from a hybrid type 1 trial examining the implementation and effectiveness of a peer-led healthy lifestyle program for overweight/obese (BMI $\geq 25$ ) clients with SMI in three supportive housing agencies [32]. Supportive housing is an important service sector for people with SMI because it combines community-based housing with a range of services addressing clients' physical and mental health, substance use treatment, and community integration needs [33].

Sample. Trained research assistants (RAs) conducted in-person screenings to assess client eligibility: supportive housing resident, aged 18 years or older, English or Spanish speaking, diagnosed with an SMI (e.g., schizophrenia, schizoaffective disorder, mood disorders), overweight/obese (i.e., BMI $\geq 25$ ), and willing to obtain medical clearance if randomized to the intervention. Exclusionary criteria included failing a capacity to consent questionnaire [34], posing a danger to self or others, receiving detoxification services for alcohol/drug abuse, reporting conditions contraindicated with participating in a weight loss intervention (e.g., recent cardiac event) [32] (See [34] for a complete list of medical contraindications), and for those 65 years or older, screening positive on the Mini-Cog Cognitive Impairment screener [35, 36]. Baseline interviews were conducted by RAs, lasted 1.5 hours on average, and participants were reimbursed $\$ 25$ for their time. All measures used in the interviews had previously been published and all participants provided written informed consent. All study procedures were approved by the [University] Institutional Review Board and the [City] Department of Public Health IRB. 


\section{Measures}

Participant Characteristics. Participants were asked to self-report demographic (e.g., sex, race/ethnicity, age, history of homelessness) and clinical characteristics, such as lifetime physician diagnosis of SMI and drug/alcohol abuse or dependence, as well as names of medications they were currently prescribed. Antipsychotic medication was categorized as first or second-generation antipsychotic (SGA).

CVD Risk Factors. Obesity was defined as a BMI of $\geq 30.0 \mathrm{~kg} / \mathrm{m}^{2}$ which was calculated using participants' height and weight ((weight [lbs] * 703) / height(in $\left.{ }^{2}\right)$ ), as measured by the RAs using wall tape and digital scales. Having high blood pressure, diabetes, and high cholesterol were defined as participants' self-report of a lifetime physician diagnosis of these conditions, as indicated by "Yes" answers to a series of questions asking "Has a doctor ever told you that you have..." for each condition [37, 38]. Smoking was defined by self-report of current smoking, whether daily or not. Dichotomous variables were created to indicate the presence (yes or no) of each of these five risk factors. A sum score reflecting the total number of co-occurring risk factors for each participant (ranging from 0 : overweight only to 5 : all risk factors present) was calculated $[25,39]$.

Health-Related Quality of Life. The Physical and Mental Health Composite Scores (PCS \& MCS) from the 12-item Short Form Health Survey (SF-12; [40]) were used to assess participants' physical and mental HRQoL. Scores range from 0 to 100, with higher scores indicating better health. The SF-12 has demonstrated reliability among populations with mental illness and co-occurring medical conditions [41], as well as validity among those who have experienced both homelessness and mental illness [42].

Behavioral and Psychiatric Functioning. The Behavior and Symptom Identification Scale (BASIS-24) consists of 24 items that ask participants to rate the frequency or amount of difficulty they experienced with a range of psychiatric symptoms and substance use issues in the past week [43]. It consists of six sub-scales comprised of 3 to 6 items assessing depression/functioning, relationships/interpersonal competence, psychotic symptoms, alcohol/drug use, emotional lability, and self-harm. Responses are rated on a 5-point likert scale ranging from 0 (no difficulty/none of the time/never) to 4 (extreme difficulty/all of the time/always). An algorithm using a weighted average generates an overall scale score ranging from 0 to 2.83 as well as subscale scores. The BASIS24 has demonstrated excellent external reliability and fair to excellent internal consistency and validity [44], including among racial/ethnic minorities [45].

Health Locus of Control. The Multidimensional Health Locus of Control (MHLC) scale consists of 24 questions that yield scores along four sub-scales which assess the degree to which individuals believe that internal and/or external factors (Chance, Powerful Others, God) contribute to their health. Sample questions include "If I take care of myself, I can avoid illness" and "Most things that affect my health happen to me by accident." Participants rated their degree of agreement with each item from 1 (strongly disagree) to 6 (strongly agree) [46]. Responses are summed for each sub-scale to produce scores ranging from 6 to 24 , with higher scores indicating greater endorsement of that dimension. The MHLC has demonstrated adequate reliability and validity in measuring locus of control beliefs, though statistical associations with related constructs tend to vary [47].

Statistical Analysis. Analyses utilized baseline data from participants enrolled in the clinical trial irrespective of subsequent random assignment to intervention or usual care. Univariate analyses were used to describe the distribution of individual risk factors and the cumulative number of CVD risk factors. Bivariate analyses (e.g., Student's t-tests, chi-squares) explored relationships between participant characteristics and each risk factor. Considering the number of CVD risk factors as a count variable, Poisson regression with robust standard errors was used to explore its correlates. No problem of overdispersion was found using a likelihood ratio test of over-dispersion parameter alpha by running the same regression model using a negative binomial distribution (Long and Freese, 2004). Finally, ordinary least squares regression was used to explore the correlates of PCS and MCS. Selection of potential correlates for regression analyses was informed by findings from existing research examining CVD risk factors and/or HRQoL among people with SMI (e.g. Newcomer and Hennekens, 2007; Lim and Lee, 2018; Neil et al., 2018). Variables were included in regression models if they were associated with the respective dependent variable (CVD risk factors, PCS, MCS) in bivariate analyses with a p-value of $<0.1$ (results available upon request). Model diagnostics including tests for normality, homoscedasticity, multicollinearity, outliers and influential cases indicated none of the model assumptions were violated (Kutner et al., 2004). Participants with missing data on any variables in the multivariate models were excluded. Eventually all models had less than $10 \%$ missing data, with $9.9 \%, 4.8 \%$, and $3.8 \%$ for each multivariate model. A two-sided p-value of 0.05 or less was used to indicate statistical significance. All analyses were performed in Stata 15.0 (StataCorp LP, College Station, TX).

Page $4 / 16$ 


\section{Results}

Participant Characteristics \& CVD Risk Factor Prevalence. Of 448 clients screened, 108 (24\%) were ineligible, most commonly for not meeting BMI or SMI criteria, or reporting an exclusionary medical condition. Of the 340 who were eligible, 314 (92\%) enrolled in the study and completed face-to-face structured baseline interviews, including having their physical measurements taken, within approximately four weeks of screening. Participant characteristics and risk factors are displayed in Table 1. Participants were 48.7 years old, on average $(s d=11.6)$. The majority were male, racial/ethnic minorities $(81.8 \%)$, primarily non-Hispanic black, with at least a high school education. Most participants had spent at least one year homeless. Most frequently reported lifetime mental health diagnoses were depression, schizophrenia/schizoaffective disorder (56.7\%), bipolar disorder (49.9\%), and co-occurring anxiety disorders (50.2\%). Participants' mean BMI was 33.7 (SD = 7.2).

\section{[INSERT TABLE 1 HERE]}

The most frequently reported risk factors were obesity, current smoking, and hypertension, with each reported by more than half of the sample, followed by high cholesterol and diabetes. Nearly all participants (94.8\%) reported at least 1 risk factor, with $19.1 \%$ reporting one, $29 \%$ reporting two, $21.3 \%$ reporting three, $17.9 \%$ reporting four, and $7.6 \%$ reporting all five. The vast majority of the sample had at least two risk factors (75.4\%) and almost half of the sample had 3 or more $(46.7 \%)$.

Bivariate analyses shown in Table 1 indicated females were more likely to report current smoking than males, while increasing age was significantly associated with reporting diabetes, hypertension, high cholesterol, and current smoking. The prevalence of obesity differed significantly by racial/ethnic group, with Hispanics having the highest percentages and non-Hispanic whites, the lowest. Compared to those with at least a high school education, participants who did not complete high school had significantly higher prevalence of diabetes, high cholesterol, and smoking. Participants who had been homeless for a year or more were more likely to be current smokers compared to those who reported less than a year of homelessness, while those with schizophrenia or schizoaffective disorder were more likely to report diabetes compared to people without either diagnosis. Those with alcohol use disorders were less likely to report diabetes but more likely to report current smoking, as were participants diagnosed with drug dependence. With respect to risk factor clustering, increasing age, having less than a high school education, and a diagnosis of schizophrenia/schizoaffective disorder were associated with having a higher number of co-occurring risk factors.

Sociodemographic and Clinical Correlates of Number of CVD Risk Factors. As seen in Table 2, Poisson regression results indicated that, after controlling for all covariates, sex, age, education and taking anti-psychotic medication were significantly related to number of CVD risk factors. Identifying as female increased the expected number of CVD risk factors by $15 \%$. For every one-year increase in age, the expected number of CVD risk factors increased by $1 \%$. Having a high school education was associated with a $17 \%$ decrease in expected number of CVD risk factors, while taking a SGA was associated with a $16 \%$ increase relative to those taking no antipsychotic medication.

\section{[INSERT TABLE 2 HERE]}

Correlates of Health-Related Quality of Life. When adjusting for other covariates in the OLS regression, number of CVD risk factors was significantly associated with PCS $(\beta=-0.15, p=.009)$, such that having a higher number of risk factors was associated with lower physical HRQoL. Sex was also significantly associated with PCS $(\beta=-2.36, p=.022)$, such that compared to males, females had lower physical HRQoL. Additionally, BASIS scores were significantly and negatively associated with PCS scores $(\beta=-1.97, p=.041)$, indicating that higher frequency and difficulty with psychiatric symptoms was associated with lower physical HRQoL.

Age was significantly associated with MCS ( $\beta=.11, p=.013)$, with increasing age associated with higher mental HRQoL. BASIS scores were significantly and negatively associated with MCS $(\beta=-10.08, p<0.001)$, with greater symptoms and lower functioning associated with lower mental HRQoL. Finally, the MHLC internal subscale was significantly associated with MCS $(\beta=0.23, p=.036)$, such that greater endorsement of internal locus of control was associated with higher mental HRQoL.

\section{Discussion}

This study examined the associations between participant characteristics, multiple CVD risk factors, and HRQoL in an ethnically/racially diverse sample of overweight/obese individuals with SMI living in supportive housing. Given the high rates of CVD 
risk in people with SMI, and the potential negative impact of multiple, co-occurring risks, it is important to understand the extent to which CVD risk factors cluster and how they impact HRQoL in this vulnerable population. Consistent with prior literature, our study sample had high rates of individual CVD risk factors [6,7,8]. Clustering of risks was common, with almost half of the sample having three or more CVD risk factors [52]. Compared to other studies examining CVD risk among individuals diagnosed with schizophrenia, our study sample had higher rates of having at least one risk factor in addition to the clustering of multiple risk factors [53, 54]. Even compared to studies of individuals with SMI who were also overweight/obese, our sample had higher rates of smoking and hypertension, and slightly higher rates of diabetes [55], suggesting that people with SMI in supportive housing represent a priority population for intervention.

Cumulative number of CVD risk factors was negatively associated with physical HRQoL, demonstrating a relationship between risk factor clustering and perceived health status and functioning. To our knowledge, this is the first study to examine the combined impact of CVD risk on HRQOL among people with SMI and findings are consistent with research available on general population samples [25]. Despite the high rates of CVD risk and medical co-morbidities of persons with SMI, inclusion of these factors in studies of determinants of HRQoL within this population is rare [48]. Consistent screening of persons with SMI, particularly those living in supportive housing, would help to identify those with clustering of multiple risk factors for CVD, who could represent high priority for intervention and risk management. Further research is needed to understand the mechanisms underlying this negative association, which could help identify potential pathways for intervention to improve functioning and health status among those with high risk. Greater mental health symptoms and lower functioning were associated with worse physical HRQoL, demonstrating the need to better understand and specify this relationship. After controlling for CVD risk factors, mental health symptoms were still associated with physical HRQoL, indicating the need to explore additional factors, such as reduced energy/lethargy, that may limit functioning and quality of life [65]. Additionally, future studies can also explore how perceptions of pain may limit physical functioning, especially given that these perceptions are associated with hopefulness and sense of self-efficacy, which are often driven by psychological functioning [66]. Consistent with other studies, women had lower physical HRQoL and a larger number of CVD risk factors, including obesity, smoking. Studies have hypothesized that lower physical HRQoL may be associated with higher number of CVD risk factors (medical comorbidity) and gender differences in how physical illness is expressed and disclosed [67, 68].

Finally, increasing age was associated with better mental HRQoL [69], as was greater internal locus of control [70], consistent with findings from prior literature in the general population. Poorer symptomatology and functioning were also associated with worse mental HRQoL. CVD risk was not significantly associated with mental HRQoL in our sample of persons with SMI, though mental health was associated with physical HRQoL. However, findings regarding the relationship between physical and mental HRQoL in this population have been inconsistent. For example, one study of persons with SMI found no significant association between physical health and mental HRQoL [22], while another found an inverse relationship between medical comorbidities and mental HRQoL [71] . Given these mixed findings, more research is needed to assess the relationship between CVD risk and mental HRQoL among people with SMI. Overall, our findings suggest the importance of including CVD risk factors in research exploring determinants of HRQoL among persons with SMI living in supportive housing. While stable housing is a necessary component for improving HRQoL, it is imperative to examine how additional factors (e.g., locus of control, social supports) influence HRQoL so that support services may target these factors as well $[26,27]$.

\section{Limitations}

This study had several limitations, beginning with the non-random sampling of participants. The sample was recruited as part of an RCT with specified inclusion and exclusion criteria, including a BMI of 25 or higher for eligibility, and thus reflects a pool at elevated risk that may be not representative of persons with SMI residing in supportive housing programs in general. Nevertheless, only $13 \%$ of individuals screened did not meet BMI criteria, suggesting that findings are likely relevant for populations served by supportive housing in urban areas. The study also used cross-sectional data, reducing our capacity to infer causality from the analyses, and a longitudinal design may better elucidate the factors that predict CVD risk and quality of life. Additionally, this study relied largely on self-report data, which may have led to underestimation of CVD risk. Objective and physiological measurements may have added nuance to study findings, allowing for analyses that could include risk factor severity (e.g., blood glucose levels) rather than a dichotomous presence/absence of risk factors. Nevertheless, the use of self-report data is consistent with prior literature analyzing CVD risk factors in the general population and question wording aligned with standardized population-based surveys (e.g., Behavioral Risk Factor Surveillance System). Finally, analyses utilized a limited set of individual-level variables; examining additional variables, such as social support, or multi-level factors, such as neighborhood characteristics, may provide a more comprehensive

Page 6/16 
understanding of CVD risk and quality of life. Despite these limitations, key strengths included a community-based participant sample with a high percentage of racial/ethnic minorities, who tend to be under-represented in SMI health research, with a range of psychiatric diagnoses, as well as considering multiple CVD risks and other factors that may influence HRQoL.

\section{Conclusion}

Persons with SMI in supportive housing experience a multitude of challenges that can negatively impact their health and quality of life. As such, the prevalence and clustering of CVD risk factors is high and frequent. Reducing CVD risk will require both expanding access to quality care and providing increased support to facilitate health behavior change for modifiable risk factors [7]. Specific strategies include increasing collaboration between physical and mental health providers through integrated care [72], regular screening for risk factors [73], expanding health supports in community settings such as supportive housing programs [31], implementing healthy lifestyle interventions targeting a spectrum of health behaviors [32, 74], and most recently, utilizing peer specialists within health programs [75]. Further, given that many of these risk factors begin to manifest early in the development of disorders such as schizophrenia, with many health indicators trending towards poorer values in the first years of treatment, interventions that focus on health promotion and CVD risk prevention are urgently during that critical time [76, 77]. Finally, additional research is needed to better understand how CVD risk and other factors influence HRQoL among persons with SMI, particularly for those in supportive housing and for women, including how best to minimize or buffer their negative impact on daily life and functioning. Given indications of widening disparities in mortality for people with SMI, reducing their risk of CVD and improving quality of life is an urgent public health priority.

\section{Abbreviations}

1. Serious Mental IIIness (SMI)

2. Cardiovascular Disease (CVD)

3. Health-related quality of life (HRQoL)

4. Body Mass Index (BMI)

5. Research Assistants (RA)

6. Multidimensional Health Locus of Control (MHLC)

7. Physical Health Composite Scores (PCS)

8. Mental Health Composite Scores (PCS \& MCS)

9. Second-generation Antipsychotic (SGA).

\section{Declarations}

\section{Ethics approval and consent to participate:}

All procedures performed in studies involving human participants were in accordance with the ethical standards of the Columbia University Institutional Review Board (CU IRB Protocol AAA07250) and the Philadelphia Department of Public Health (PDPH IRB Protocol 2015-01) and with the 1964 Helsinki declaration and its later amendments or comparable ethical standards. Written informed consent was obtained from all individual participants included in the study.

\section{Consent for publication: N/A}

\section{Availability of data and materials:}

The datasets used and/or analysed during the current study are available from the corresponding author on reasonable request Competing interests: The authors declare that they have no competing interests.

\section{Funding:}

This study was funded by the National Institute of Mental Health (grant number R01MH104574).NIMH had no role in the design of the study and collection, analysis, and interpretation of data and in the writing of the manuscript. 
Authors' contributions:

AS and LJC participated in the study development and design. XW and CW conducted the data analysis. KR and CW contributed to the interpretation of the analysis. NL and AS drafted the manuscript. LJC, LB, and XW contributed to the editing, revision, and preparation of the manuscript. All authors approved the final version of the manuscript

\section{Acknowledgements: N/A}

\section{References}

1. Carroll MD, Fryar CD, Nguyen DT, National Center for Health Statistics (US). Total and high-density lipoprotein cholesterol in adults: United States, 2011-2014. US Department of Health and Human Services, Centers for Disease Control and Prevention, National Center for Health Statistics. 2015.

2. Baciu A, Negussie Y, Geller A, Weinstein JN. National Academies of Sciences, Engineering, and Medicine. Communities in Action: Pathways to Health Equity. Washington, DC: The National Academies Press. 2017; doi:10.17226/24624.

3. Colton CW, Manderscheid RW. Congruencies in increased mortality rates, years of potential life lost, and causes of death among public mental health clients in eight states. Prev Chronic Dis. 2006;3(2).

4. Walker ER, McGee RE, Druss BG. Mortality in mental disorders and global disease burden implications: a systematic review and meta-analysis. JAMA Psychiatry. 2015;72(4):334-41.

5. Hayes JF, Marston L, Walters K, King MB, Osborn DP. Mortality gap for people with bipolar disorder and schizophrenia: UK-based cohort study 2000-2014. Br J Psychiatry. 2017; 211(3):175-81

6. Newcomer JW, Hennekens CH. Severe mental illness and risk of cardiovascular disease. JAMA. 2007;298(15):1794-6.

7. De Hert M, Correll CU, Bobes J, Cetkovich-Bakmas MA, Cohen DA, Asai I, et al. Physical illness in patients with severe mental disorders. I. Prevalence, impact of medications and disparities in health care. World Psychiatry. 2011;10(1):52-77.

8. Sokal J, Messias E, Dickerson FB, Kreyenbuhl J, Brown CH, Goldberg RW, et al. Comorbidity of medical illnesses among adults with serious mental illness who are receiving community psychiatric services. J. Nerv. Ment. Dis. 2004;192(6):421-7.

9. Carliner H, Collins PY, Cabassa LJ, McNallen A, Joestl SS, Lewis-Fernández R. Prevalence of cardiovascular risk factors among racial and ethnic minorities with schizophrenia spectrum and bipolar disorders: a critical literature review. Compr. Psychiatry. 2014;55(2):233-47.

10. O'Connell JJ, Oppenheimer SC, Judge CM, Taube RL, Blanchfield BB, Swain SE, et al. The Boston Health Care for the Homeless Program: a public health framework. Am J Public Health. 2010;100(8):1400-8.

11. Gozdzik A, Salehi R, O'Campo P, Stergiopoulos V, Hwang SW. Cardiovascular risk factors and 30-year cardiovascular risk in homeless adults with mental illness. BMC Public Health. 2015;15(1):165.

12. Weinstein LC, Henwood BF, Matejkowski J, Santana AJ. Moving from street to home: health status of entrants to a housing first program. J Prim Care Community Health. 2011; 2(1):11-5.

13. Reinikainen J, Laatikainen T, Karvanen J, Tolonen H. Lifetime cumulative risk factors predict cardiovascular disease mortality in a 50-year follow-up study in Finland. Int J Epidemiol. 2015; 44(1):108-16.

14. Boudreau DM, Malone DC, Raebel MA, Fishman PA, Nichols GA, Feldstein AC, et al. Health care utilization and costs by metabolic syndrome risk factors. Metab Syndr Relat Disord. 2009;7(4):305-14.

15. Sullivan PW, Ghushchyan V, Wyatt HR, Wu EQ, Hill JO. Impact of cardiometabolic risk factor clusters on health-related quality of life in the US. Obesity. 2007;15(2):511-.

16. Chambers BA, Guo SS, Siervogel R, Hall G, Chumlea WC. Cumulative effects of cardiovascular disease risk factors on quality of life. J Nutr Health Aging. 2002; 6(3):179-84.

17. Karimi M, Brazier J. Health, health-related quality of life, and quality of life: what is the difference?. Pharmacoeconomics. 2016; 34(7):645-9.

18. Zuluaga MC, Guallar-Castillón P, López-García E, Banegas JR, Conde-Herrera M, Olcoz-Chiva M, et al. Generic and disease-specific quality of life as a predictor of long-term mortality in heart failure. Eur J Heart Fail. 2010;12(12):1372- 
19. Dorr DA, Jones SS, Burns L, Donnelly SM, Brunker CP, Wilcox A, et al. Use of health-related, quality-of-life metrics to predict mortality and hospitalizations in community-dwelling seniors. J Am Geriatrics Society. 2006; 54(4):667-73.

20. Arnold LM, Witzeman KA, Swank ML, McElroy SL, Keck Jr PE. Health-related quality of life using the SF-36 in patients with bipolar disorder compared with patients with chronic back pain and the general population. J. Affect. Disord. 2000;57(1-3):235-9.

21. Folsom DP, Depp C, Palmer BW, Mausbach BT, Golshan S, Fellows I, et al. Physical and mental health-related quality of life among older people with schizophrenia. Schizophr Res. 2009;108(1-3):207-13.

22. Barnes AL, Murphy ME, Fowler CA, Rempfer MV. Health-related quality of life and overall life satisfaction in people with serious mental illness. Schizophr Res Treatment. 2012.

23. Neil AL, Carr VJ, Mackinnon A, Foley DL, Morgan VA. Health-related quality of life in people living with psychotic illness and factors associated with its variation. Value Health. 2018; 21(8):1002-9.

24. Vancampfort D, Probst M, Scheewe T, Maurissen K, Sweers K, Knapen J, et al. Lack of physical activity during leisure time contributes to an impaired health related quality of life in patients with schizophrenia. Schizophr Res. 2011;129(2-3):122-7.

25. Li C, Ford ES, Mokdad AH, Balluz LS, Brown DW, Giles WH. Clustering of cardiovascular disease risk factors and health-related quality of life among US adults. Value Health. 2008;11(4):689-99.

26. Lemoine C, Loubiere S, Tinland A, Boucekine M, Girard V, Auquier P. Long-term effects of a housing support intervention in homeless people with severe mental illness. Eur J Public Health. 2019; 29(Supplement_4):ckz185-086.

27. Tsai J, Gelberg L, Rosenheck RA. Changes in physical health after supported housing: Results from the Collaborative Initiative to End Chronic Homelessness. J Gen Intern Med. 2019; 34(9):1703-8.

28. Garey L, Reitzel LR, Kendzor DE, Businelle MS. The potential explanatory role of perceived stress in associations between subjective social status and health-related quality of life among homeless smokers. Behav Modif. 2016;40(1-2):303-24.

29. Tsui Jl, Bangsberg DR, Ragland K, Hall CS, Riley ED. The impact of chronic hepatitis C on health-related quality of life in homeless and marginally housed individuals with HIV. AIDS Behav. 2007;11(4):603-10.

30. Kertesz SG, Larson MJ, Horton NJ, Winter M, Saitz R, Samet JH. Homeless chronicity and health-related quality of life trajectories among adults with addictions. Med Care. 2005:574-85.

31. Henwood BF, Cabassa LJ, Craig CM, Padgett DK. Permanent supportive housing: addressing homelessness and health disparities?. Am J Public Health. 2013; 103(S2):S188-92.

32. Removed for review

33. Nelson G, Laurier W. Housing for people with serious mental illness: Approaches, evidence, and transformative change. J Soc \& Soc Welfare. 2010; 37:123.

34. Zayas LH, Cabassa LJ, Perez MC. Capacity-to-consent in psychiatric research: Development and preliminary testing of a screening tool. Res Soc Work Pract. 2005;15(6):545-56.

35. Borson S, Scanlan JM, Chen P, Ganguli M. The Mini-Cog as a screen for dementia: validation in a population-based sample. J Am Geriatr Soc. 2003;51(10):1451-4.

36. Palmer, R.M., Meldon, S.W., 2003. Acute care. In W. R. Hazzard (Ed.), Principles of geriatric medicine and gerontology., Boston: McGraw-Hill, pp. 157-168.

37. Centers for Disease Control and Prevention. Behavioral Risk Factor Surveillance System Survey Questionnaire. Atlanta, Georgia: U.S. Department of Health and Human Services, Centers for Disease Control and Prevention. 2011. https://www.cdc.gov/brfss/questionnaires/pdf-ques/2011brfss.pdf (accessed 6 August 2019).

38. Baicker K, Taubman SL, Allen HL, Bernstein M, Gruber JH, Newhouse JP et al. The Oregon experiment-effects of Medicaid on clinical outcomes. N Engl J Med. 2013;368(18):1713-22.

39. Daviglus ML, Talavera GA, Avilés-Santa ML, Allison M, Cai J, Criqui MH, et al. Prevalence of major cardiovascular risk factors and cardiovascular diseases among Hispanic/Latino individuals of diverse backgrounds in the United States. JAMA. 2012; 308(17):1775-84.

40. Ware Jr JE, Kosinski M, Keller SD. A 12-Item Short-Form Health Survey: construction of scales and preliminary tests of reliability and validity. Med Care. 1996:220-33.

41. Huo T, Guo Y, Shenkman E, Muller K. Assessing the reliability of the short form 12 (SF-12) health survey in adults with mental health conditions: a report from the wellness incentive and navigation (WIN) study. Health Qual Life Outcomes. 2018; $16(1): 34$.

Page 9/16 
42. Chum A, Skosireva A, Tobon J, Hwang S. Construct validity of the SF-12v2 for the homeless population with mental illness: an instrument to measure self-reported mental and physical health. PLoS One. 2016;11(3).

43. Eisen, S. V., Normand, S. L. T., Belanger, A. J., Gevorkian, S., \& Irvin, E. A. BASIS-32® and the Revised Behavior and Symptom Identification Scale (BASIS-R). 2004.

44. Eisen SV, Normand SL, Belanger AJ, Spiro A, Esch D. The revised behavior and symptom identification scale (BASIS-R): reliability and validity. Med Care. 2004:1230-41.

45. Eisen SV, Gerena M, Ranganathan G, Esch D, Idiculla T. Reliability and validity of the BASIS-24@ mental health survey for whites, African-Americans, and Latinos. J Behav Health Serv Res. 2006;33(3):304.

46. Wallston KA, Strudler Wallston B, DeVellis R. Development of the multidimensional health locus of control (MHLC) scales. Health Education Monographs. 1978;6(1):160-70.

47. Kassianos AP, Symeou M, loannou M. The health locus of control concept: Factorial structure, psychometric properties and form equivalence of the Multidimensional Health Locus of Control scales. Health Psych Open. 2016 Oct;3(2):2055102916676211.

48. Lim MW, Lee J. Determinants of health-related quality of life in schizophrenia: Beyond the medical model. Front Psychiatry. 2018; 9:712.

49. Long JS, Freese J., 2014. Regression Models for Categorical Dependent Variables Using Stata, Third Edition. College Station, Texas: Stata Press

50. Kutner, MH, Nachtsheim CJ, Neter J., 2004. Applied Linear Regression Models, 4th Edition, McGraw Hills/Irwin.

51. StataCorp, 2017. Stata Statistical Software: Release 15. College Station, TX: StataCorp LLC.

52. De Hert M, Schreurs V, Vancampfort D, Van Winkel R. Metabolic syndrome in people with schizophrenia: a review. World Psychiatry. 2009;8(1):15-22.

53. Chiu M, Rahman F, Vigod S, Wilton AS, Kurdyak P. Temporal trends in cardiovascular disease risk factor profiles in a populationbased schizophrenia sample: a repeat cross-sectional study. J Epidemiol Community Health. 2018;72(1):71-7.

54. Bresee LC, Majumdar SR, Patten SB, Johnson JA. Prevalence of cardiovascular risk factors and disease in people with schizophrenia: a population-based study. Schizophr Res. 2010;117(1):75-82.

55. Yarborough BJ, Leo MC, Stumbo S, Perrin NA, Green CA. STRIDE: a randomized trial of a lifestyle intervention to promote weight loss among individuals taking antipsychotic medications. BMC Psychiatry. 2013 Dec;13(1):238.

56. Dickerson F, Schroeder J, Katsafanas E, Khushalani S, Origoni AE, Savage C, et al. Cigarette smoking by patients with serious mental illness, 1999-2016: an increasing disparity. Psychiatr Serv. 2018;69(2):147-53.

57. Baggett TP, Rigotti NA. Cigarette smoking and advice to quit in a national sample of homeless adults. Am J Prev Med. 2010;39(2):164-72.

58. Filia SL, Baker AL, Gurvich CT, Richmond R, Lewin TJ, Kulkarni J. Gender differences in characteristics and outcomes of smokers diagnosed with psychosis participating in a smoking cessation intervention. Psychiatry Res. 2014;215(3):586-93.

59. Henwood BF, Byrne T, Scriber B. Examining mortality among formerly homeless adults enrolled in Housing First: An observational study. BMC Public Health. 2015;15(1):1209.

60. DeWalt DA, Berkman ND, Sheridan S, Lohr KN, Pignone MP. Literacy and health outcomes. J Gen Intern Med. 2004;19(12):122839.

61. Chang SC, Lu ML. Metabolic and cardiovascular adverse effects associated with treatment with antipsychotic drugs. J Exp Clin Med. 2012; 4(2):103-7.

62. Kahl KG, Westhoff-Bleck M, Krueger TH. Effects of psychopharmacological treatment with antipsychotic drugs on the vascular system. Vascul Pharmacol. 2018;100:20-5.

63. Keenan TE, Yu A, Cooper LA, Appel LJ, Guallar E, Gennusa III JV, et al. Racial patterns of cardiovascular disease risk factors in serious mental illness and the overall US population. Schizophr Res. 2013;150(1):211-6.

64. Cabassa LJ, Humensky J, Druss B, Lewis-Fernández R, Gomes AP, Wang S, et al. Do race, ethnicity, and psychiatric diagnoses matter in the prevalence of multiple chronic medical conditions?. Med Care. 2013;51(6):540.

65. Connell J, Brazier J, O'Cathain A, Lloyd-Jones M, Paisley S. Quality of life of people with mental health problems: a synthesis of qualitative research. Health Qual Life Outcomes. 2012;10(1):138. 
66. Pulvers K, Hood A. The role of positive traits and pain catastrophizing in pain perception. Curr Pain Headache Rep. 2013;17(5):330.

67. de la Cruz MS, Lai Z, Goodrich DE, Kilbourne AM. Gender differences in health-related quality of life in patients with bipolar disorder. Arch Womens Ment Health. 2013;16(4):317-23.

68. Wilson DH, Chittleborough CR, Kirke K, Grant JF, Ruffin RE. The health-related quality of life of male and female heavy smokers. Sozial-und Präventivmedizin/Social Prev Med. 2004 Dec 1;49(6):406-12.

69. Hopman WM, Harrison MB, Coo H, Friedberg E, Buchanan M, VanDenKerkhof EG. Associations between chronic disease, age and physical and mental health status. Chronic Dis Can. 2009; 29(3):108-6.

70. Helvik AS, Bjørkløf GH, Corazzini K, Selbaek G, Laks J, Østbye T, et al. Are coping strategies and locus of control orientation associated with health-related quality of life in older adults with and without depression?. Arch Gerontol Geriatr. 2016 May 1;64:130-7.

71. Dickerson FB, Brown $\mathrm{CH}$, Kreyenbuhl JA, Fang L, Goldberg RW, Wohlheiter K, et al. Obesity among individuals with serious mental illness. Acta Psychiatr Scand. 2006;113(4):306-13.

72. Rodgers M, Dalton J, Harden M, Street A, Parker G, Eastwood A. Integrated care to address the physical health needs of people with severe mental illness: a rapid review. Southampton (UK): NIHR Journals Library (Health Serv Deliv Res, No. 4.13). 2016.

73. Viron M, Baggett T, Hill M, Freudenreich 0 . Schizophrenia for primary care providers: How to contribute to the care of a vulnerable patient population. Am J Med. 2012;125(3):223-30.

74. Naslund JA, Whiteman KL, McHugo GJ, Aschbrenner KA, Marsch LA, Bartels SJ. Lifestyle interventions for weight loss among overweight and obese adults with serious mental illness: a systematic review and meta-analysis. Gen Hosp Psychiatry. 2017; 47:83-102.

75. Cabassa LJ, Camacho D, Vélez-Grau CM, Stefancic A. Peer-based health interventions for people with serious mental illness: a systematic literature review. J Psychiatr Res. 2017; 84:80-9.

76. Pérez-Iglesias R, Martínez-García O, Pardo-Garcia G, Amado JA, Garcia-Unzueta MT, Tabares-Seisdedos R, et al. Course of weight gain and metabolic abnormalities in first treated episode of psychosis: the first year is a critical period for development of cardiovascular risk factors. Int J Neuropsychopharmacol. 2014 Jan 1;17(1):41-51.

77. Phutane VH, Tek C, Chwastiak L, Ratliff JC, Ozyuksel B, Woods SW, et al. Cardiovascular risk in a first-episode psychosis sample: a 'critical period' for prevention?. Schizophr Res. 2011;127(1-3):257-61.

\section{Tables}

Table 1. CVD Risk Factors by Participant Characteristics 


\begin{tabular}{|c|c|c|c|c|c|c|c|c|c|c|}
\hline \multirow{2}{*}{$\begin{array}{l}\text { CVD Risk } \\
\text { Factors }\end{array}$} & \multirow[t]{2}{*}{ Total } & \multirow{2}{*}{$\begin{array}{l}\text { Sex }^{b} \\
\text { Male }\end{array}$} & \multirow[b]{2}{*}{ Female } & \multirow[t]{2}{*}{$\mathrm{Age}^{\mathrm{c}}$} & \multicolumn{4}{|c|}{ Race/Ethnicity } & \multicolumn{2}{|l|}{ Education } \\
\hline & & & & & $\begin{array}{l}\text { Non- } \\
\text { Hisp. } \\
\text { White }\end{array}$ & $\begin{array}{l}\text { Non- } \\
\text { Hisp. } \\
\text { Black }\end{array}$ & $\begin{array}{l}\text { Non- } \\
\text { Hisp. } \\
\text { Other }\end{array}$ & Hisp. & $\begin{array}{l}\text { Less than } \\
\text { high } \\
\text { school }\end{array}$ & $\begin{array}{l}\text { High } \\
\text { school or } \\
\text { greater }\end{array}$ \\
\hline $\begin{array}{l}\text { Sample n (\%)a } \\
\text { or Mean (SD) }\end{array}$ & 314 & $\begin{array}{l}180 \\
(57.3)\end{array}$ & $\begin{array}{l}133 \\
(42.4)\end{array}$ & $\begin{array}{l}48.7 \\
(11.6)\end{array}$ & $\begin{array}{l}57 \\
(18.2)\end{array}$ & $\begin{array}{l}181 \\
(57.6)\end{array}$ & $\begin{array}{l}37 \\
(11.8)\end{array}$ & $\begin{array}{l}39 \\
(12.4)\end{array}$ & $117(37.3)$ & $193(61.5)$ \\
\hline \multicolumn{11}{|l|}{ Obesity } \\
\hline No & $\begin{array}{l}113 \\
(36.0)\end{array}$ & $\begin{array}{l}72 \\
(40)\end{array}$ & $40(30)$ & $50(11.7)$ & $28(49)$ & $60(33)$ & $16(46)$ & $8(21)$ & $39(33)$ & $73(38)$ \\
\hline Yes & $\begin{array}{l}201 \\
(64.0)\end{array}$ & $\begin{array}{l}108 \\
(60)\end{array}$ & $93(70)$ & $\begin{array}{l}47.9 \\
(11.4)\end{array}$ & $29(51)$ & $121(67)$ & $19(54)$ & $\begin{array}{l}31 \\
(79)\end{array}$ & $78(67)$ & $120(62)$ \\
\hline Statistic & & 3.28 & & 1.53 & $10.40 *$ & & & & 0.64 & \\
\hline \multicolumn{11}{|l|}{ Diabetes } \\
\hline No & $\begin{array}{l}212 \\
(67.5)\end{array}$ & $\begin{array}{l}122 \\
(58)\end{array}$ & $89(42)$ & $\begin{array}{l}46.7 \\
(12.2)\end{array}$ & $46(81)$ & $\begin{array}{l}113 \\
(62)\end{array}$ & $\begin{array}{l}24 \\
(69)\end{array}$ & $\begin{array}{l}28 \\
(72)\end{array}$ & $66(56)$ & $144(75)$ \\
\hline Yes & $\begin{array}{l}102 \\
(32.5)\end{array}$ & $\begin{array}{l}58 \\
(57)\end{array}$ & $44(43)$ & $\begin{array}{l}52.7 \\
(8.9)\end{array}$ & $11(19)$ & $68(38)$ & $11(31)$ & $\begin{array}{l}11 \\
(28)\end{array}$ & $51(44)$ & $49(25)$ \\
\hline Statistic & & 0.03 & & $-4.43^{\star \star \star}$ & 7.01 & & & & 11.04 ** & \\
\hline \multicolumn{11}{|l|}{ Hyper-tension } \\
\hline No & $\begin{array}{l}141 \\
(44.9)\end{array}$ & $\begin{array}{l}77 \\
(55)\end{array}$ & $63(45)$ & $\begin{array}{l}43.7 \\
(12.8)\end{array}$ & $28(49)$ & $74(41)$ & $17(49)$ & $\begin{array}{l}21 \\
(54)\end{array}$ & $45(38)$ & $94(49)$ \\
\hline Yes & $\begin{array}{l}173 \\
(55.1)\end{array}$ & $\begin{array}{l}103 \\
(60)\end{array}$ & $70(40)$ & $\begin{array}{l}52.7 \\
(8.6)\end{array}$ & $29(51)$ & $\begin{array}{l}107 \\
(59)\end{array}$ & $18(51)$ & $\begin{array}{l}28 \\
(72)\end{array}$ & $72(62)$ & $99(51)$ \\
\hline Statistic & & 0.65 & & $-7.37^{\star \star \star}$ & 3.04 & & & & 3.09 & \\
\hline \multicolumn{11}{|c|}{ High Cholesterol } \\
\hline No & $\begin{array}{l}200 \\
(63.7)\end{array}$ & $\begin{array}{l}118 \\
(66)\end{array}$ & $81(61)$ & $\begin{array}{l}47.5 \\
(12)\end{array}$ & $32(56)$ & $\begin{array}{l}121 \\
(67)\end{array}$ & $20(57)$ & $\begin{array}{l}26 \\
(67)\end{array}$ & $65(56)$ & $131(68)$ \\
\hline Yes & $\begin{array}{l}114 \\
(36.3)\end{array}$ & $\begin{array}{l}62 \\
(34)\end{array}$ & $52(39)$ & $\begin{array}{l}50.7 \\
(10.4)\end{array}$ & $25(44)$ & $60(33)$ & $15(43)$ & $\begin{array}{l}13 \\
(33)\end{array}$ & $52(44)$ & $62(32)$ \\
\hline Statistic & & 0.72 & & $-2.42^{\star}$ & 2.99 & & & & $4.76^{\star}$ & \\
\hline \multicolumn{11}{|l|}{$\begin{array}{l}\text { Current } \\
\text { Smoking }\end{array}$} \\
\hline No & $\begin{array}{l}117 \\
(37.3)\end{array}$ & $\begin{array}{l}77 \\
(43)\end{array}$ & $39(29)$ & $\begin{array}{l}47 \\
(12.6)\end{array}$ & $21(37)$ & $64(35)$ & $12(34)$ & $\begin{array}{l}20 \\
(51)\end{array}$ & $33(28)$ & $82(42)$ \\
\hline Yes & $\begin{array}{l}197 \\
(62.6)\end{array}$ & $\begin{array}{l}103 \\
(57)\end{array}$ & $94(71)$ & $\begin{array}{l}49.6 \\
(10.8)\end{array}$ & $36(63)$ & $\begin{array}{l}117 \\
(65)\end{array}$ & $23(66)$ & $\begin{array}{l}19 \\
(49)\end{array}$ & $84(72)$ & $111(58)$ \\
\hline Statistic & & $5.94 *$ & & $-1.98^{*}$ & 3.68 & & & & $6.37 *$ & \\
\hline
\end{tabular}


\# of CVD Risk

Factors $^{\mathrm{d}}$

Mean/

2.50

2.41

2.64

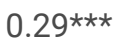

2.26

2.61

2.46

2.36

2.88

2.28

Correlation

SD

1.82

1.29

2.36

1.2

1.34

1.34

1.4

1.39

1.5

Statistic

$-1.56$

1.21

$3.93^{\star \star \star}$

Page 13/16 


\begin{tabular}{|c|c|c|c|c|c|c|c|c|c|c|c|}
\hline \multirow[t]{3}{*}{$\begin{array}{l}\text { CVD Risk } \\
\text { Factors }\end{array}$} & \multicolumn{2}{|c|}{$\begin{array}{l}\text { Lifetime Days } \\
\text { Homeless }\end{array}$} & \multicolumn{2}{|c|}{ Diagnosis } & \multicolumn{4}{|c|}{ Substance Use } & \multicolumn{3}{|c|}{ Antipsychotic Type } \\
\hline & \multirow{2}{*}{$\begin{array}{l}<1 \\
\text { year }\end{array}$} & \multirow{2}{*}{$\begin{array}{l}>= \\
1 \\
\text { year }\end{array}$} & \multirow{2}{*}{$\begin{array}{l}\text { No } \\
\text { Schizo- } \\
\text { phrenia/ } \\
\text { affective }\end{array}$} & \multirow{2}{*}{$\begin{array}{l}\text { Schizo- } \\
\text { phrenia/ } \\
\text { affective }\end{array}$} & \multirow{2}{*}{$\begin{array}{l}\text { No drug } \\
\text { abuse/ } \\
\text { depend. }\end{array}$} & \multirow{2}{*}{$\begin{array}{l}\text { Drug } \\
\text { abuse/ } \\
\text { depend. }\end{array}$} & \multirow{2}{*}{$\begin{array}{l}\text { No } \\
\text { alcohol } \\
\text { use/ } \\
\text { depend. }\end{array}$} & \multirow{2}{*}{$\begin{array}{l}\text { Alcohol } \\
\text { abuse/ } \\
\text { depend. }\end{array}$} & \multirow[t]{2}{*}{ None } & \multirow[t]{2}{*}{$\begin{array}{l}\text { First } \\
\text { Gen. }\end{array}$} & \multirow{2}{*}{$\begin{array}{l}\text { Second } \\
\text { Gen. }\end{array}$} \\
\hline & & & & & & & & & & & \\
\hline \multirow{2}{*}{$\begin{array}{l}\text { Sample n } \\
\text { (\%) or } \\
\text { Mean (SD) }\end{array}$} & \multirow{2}{*}{$\begin{array}{l}113 \\
(34.0)\end{array}$} & \multirow{2}{*}{$\begin{array}{l}177 \\
(56.4)\end{array}$} & \multirow{2}{*}{$\begin{array}{l}133 \\
(42.4)\end{array}$} & \multirow{2}{*}{$\begin{array}{l}178 \\
(56.7)\end{array}$} & \multirow{2}{*}{$\begin{array}{l}210 \\
(66.9)\end{array}$} & \multirow{2}{*}{$\begin{array}{l}102 \\
(32.5)\end{array}$} & 234 & 78 & \multirow{2}{*}{$\begin{array}{l}117 \\
(37.3)\end{array}$} & \multirow{2}{*}{$\begin{array}{l}40 \\
(12.7)\end{array}$} & \multirow{2}{*}{$\begin{array}{l}157 \\
(50.0)\end{array}$} \\
\hline & & & & & & & $(74.5)$ & $(24.8)$ & & & \\
\hline
\end{tabular}

\section{Obesity}

\begin{tabular}{|c|c|c|c|c|c|c|c|c|c|c|c|}
\hline No & $\begin{array}{l}43 \\
(38)\end{array}$ & $\begin{array}{l}59 \\
\text { (33) }\end{array}$ & $44(33)$ & $67(38)$ & 74 (35) & $37(36)$ & $82(35)$ & 29 (37) & $\begin{array}{l}48 \\
(41)\end{array}$ & $\begin{array}{l}15 \\
(37)\end{array}$ & $50(32)$ \\
\hline Yes & $\begin{array}{l}70 \\
(62)\end{array}$ & $\begin{array}{l}118 \\
(67)\end{array}$ & $89(67)$ & $111(62)$ & $\begin{array}{l}136 \\
(65)\end{array}$ & $65(64)$ & $\begin{array}{l}152 \\
(65)\end{array}$ & $49(63)$ & $\begin{array}{l}69 \\
(59)\end{array}$ & $\begin{array}{l}25 \\
(63)\end{array}$ & $\begin{array}{l}107 \\
(68)\end{array}$ \\
\hline Statistic & 0.67 & & 0.69 & & 0.03 & & 0.12 & & 2.50 & & \\
\hline
\end{tabular}

\section{Diabetes}

\begin{tabular}{llllllllllll} 
No & 74 & 121 & $104(78)$ & $107(60)$ & 141 & $70(69)$ & 151 & $60(77)$ & 88 & 25 & $99(63)$ \\
& $(65)$ & $(68)$ & & & $(67)$ & & $(65)$ & & $(75)$ & $(63)$ & \\
Yes & 39 & 56 & $29(22)$ & $71(40)$ & $69(33)$ & $32(31)$ & $83(35)$ & $18(23)$ & 29 & 15 & $58(37)$ \\
& $(35)$ & $(32)$ & & & & & & & $(25)$ & $(37)$ & \\
\hline
\end{tabular}

Hyper-
tension

$\begin{array}{llllllllllll}\text { No } & 57 & 77 & 64(48) & 77(43) & 99(47) & 42(41) & \begin{array}{l}108 \\ (46)\end{array} & 33(42) & 56 & 17 & 68(43) \\ & (50) & (44) & & & & & & (48) & (43) & \\ \text { Yes } & 56 & 100 & 69(52) & 101(57) & \begin{array}{l}111 \\ (53)\end{array} & 60(59) & \begin{array}{l}126 \\ (54)\end{array} & 45(58) & 61 & 23 & 89(57) \\ & (50) & (56) & & & & & (52) & (57) & \\ \text { Statistic } & 1.34 & & 0.73 & & 0.99 & & 0.35 & & 0.67 & \end{array}$

High

Cholesterol

$\begin{array}{llllllllllll}\text { No } & \begin{array}{l}68 \\ (60)\end{array} & \begin{array}{l}118 \\ (67)\end{array} & 88(66) & 109(61) & \begin{array}{l}132 \\ (63)\end{array} & 66(65) & \begin{array}{l}150 \\ (64)\end{array} & 48(62) & 79 & 23 & 98(62) \\ \text { Yes } & 45 & 59 & 45(34) & 69(39) & 78(37) & 36(35) & 84(36) & 30(38) & 38 & 17 & 59(38) \\ & (40) & (33) & & & & & & & (58) & (42) & \\ \text { Statistic } & 1.26 & & 0.80 & & 0.10 & & 0.17 & & 1.51 & \end{array}$

Current

Smoking

\begin{tabular}{|c|c|c|c|c|c|c|c|c|c|c|c|}
\hline No & $\begin{array}{l}53 \\
(47)\end{array}$ & $\begin{array}{l}58 \\
\text { (33) }\end{array}$ & $56(42)$ & $61(34)$ & $93(44)$ & $24(24)$ & $97(41)$ & $20(26)$ & $\begin{array}{l}47 \\
(40)\end{array}$ & $9(23)$ & $61(39)$ \\
\hline Yes & $\begin{array}{l}60 \\
(53)\end{array}$ & $\begin{array}{l}119 \\
(67)\end{array}$ & 77 (58) & $117(66)$ & $\begin{array}{l}117 \\
(56)\end{array}$ & $77(76)$ & $\begin{array}{l}137 \\
(59)\end{array}$ & $58(74)$ & $\begin{array}{l}70 \\
(60)\end{array}$ & $\begin{array}{l}31 \\
(77)\end{array}$ & $96(61)$ \\
\hline
\end{tabular}




\begin{tabular}{|c|c|c|c|c|c|c|c|c|c|c|c|}
\hline Statistic & $5.83^{*}$ & \multicolumn{3}{|c|}{1.99} & \multicolumn{2}{|c|}{ 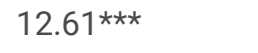 } & \multicolumn{2}{|l|}{$6.24^{*}$} & \multicolumn{3}{|l|}{4.32} \\
\hline $\begin{array}{l}\text { \# of CVD } \\
\text { Risk } \\
\text { Factors }\end{array}$ & & & & & & & & & & & \\
\hline $\begin{array}{l}\text { Mean/ } \\
\text { Correlation }\end{array}$ & 2.39 & 2.56 & 2.32 & 2.63 & 2.43 & 2.64 & 2.49 & 2.55 & 2.28 & 2.76 & 2.6 \\
\hline SD & 1.35 & 1.33 & 1.33 & 1.32 & 1.31 & 1.38 & 1.37 & 1.23 & 1.38 & 1.35 & 1.27 \\
\hline Statistic & -1.02 & & $-2.01 *$ & & -1.33 & & -0.37 & & 2.90 & & \\
\hline
\end{tabular}

Notes: aPercentages of participant characteristics do not always add up to $100 \%$ due to missing data for some variables. ${ }^{\text {b }}$ Other sex category was excluded from all analyses due to $n=1$. 'Student's $t$ test was applied, otherwise Chi-square was used; ${ }^{d}$ Poisson regression with robust standard errors was used. * $p<.05$, ** $p<.01$, ${ }^{\star \star *} p<.001$

Table 2. Regression Analysis of Cumulative Number of CVD risk factors

\begin{tabular}{|c|c|c|}
\hline & $\begin{array}{l}\text { Estimated Coefficient } \\
\beta\end{array}$ & $\begin{array}{l}\text { Incidence Rate Ratio } \\
\exp (\beta)\end{array}$ \\
\hline \multicolumn{3}{|l|}{ Sex (Ref: male) } \\
\hline Female & $0.14^{*}$ & 1.15 \\
\hline Age & $0.01^{\star * *}$ & 1.01 \\
\hline \multicolumn{3}{|c|}{ Race (Ref: Non-Hispanic white) } \\
\hline Non-Hispanic Black & 0.09 & 1.09 \\
\hline Non-Hispanic Other & 0.03 & 1.03 \\
\hline Hispanic & 0.03 & 1.04 \\
\hline \multicolumn{3}{|l|}{ Education (Ref: $\geq \mathrm{HS}$ ) } \\
\hline$<\mathrm{HS}$ & $0.19 * \star$ & 1.21 \\
\hline \multicolumn{3}{|c|}{ Schizophrenia/Schizoaffective disorder (Ref: No) } \\
\hline Yes & 0.05 & 1.05 \\
\hline \multicolumn{3}{|l|}{ Lifetime Days Homeless } \\
\hline$\geq 1$ year & 0.05 & 1.05 \\
\hline $\begin{array}{l}\text { Drug abuse/dependence } \\
\text { (Ref: No) }\end{array}$ & & \\
\hline Yes & 0.12 & 1.13 \\
\hline \multicolumn{3}{|c|}{ Alcohol abuse/dependence (Ref: No) } \\
\hline Yes & -0.07 & 0.93 \\
\hline \multicolumn{3}{|l|}{$\begin{array}{l}\text { Antipsychotic Medication } \\
\text { (Ref: No) }\end{array}$} \\
\hline First Generation & 0.16 & 1.18 \\
\hline Second Generation & $0.15^{\star}$ & 1.16 \\
\hline
\end{tabular}


Note: ${ }^{*} p<0.05,{ }^{* \star} p<0.01,{ }^{\star \star \star} p<0.001$ two-tailed test

Table 3. Regression Analysis for Physical Health Quality of Life

\begin{tabular}{|lll|}
\hline & Coefficient & SE \\
\hline Sex (Ref: male) & & \\
\hline Female & -2.36 & $1.02^{\star}$ \\
\hline Age & -0.07 & 0.05 \\
\hline BASIS total & -1.97 & $1.00^{\star}$ \\
\hline MHLC & & \\
\hline Chance Locus & -0.04 & 0.9 \\
\hline God Locus & -0.08 & 0.06 \\
\hline \# of CVD Risk Factors & -1.05 & $0.4 *$ \\
\hline
\end{tabular}

Note: ${ }^{*} p<0.05,{ }^{* \star} \mathrm{p}<0.01,{ }^{* \star *} \mathrm{p}<0.001$ two-tailed test

Table 4. Regression Analysis for Mental Health Quality of Life

\begin{tabular}{|lll|}
\hline & Coefficient & SE \\
\hline Age & 0.11 & $0.05^{\star}$ \\
\hline BASIS total & -10.08 & $1.00^{\star *}$ \\
\hline Substance Use & & \\
\hline Drug abuse/dependence (Ref: No) & & \\
\hline \multicolumn{1}{|c|}{ Yes } & -2.31 & 1.32 \\
\hline Alcohol abuse/dependence (Ref: No) & & \\
\hline Yes & 1.43 & 1.44 \\
\hline Atypical antipsychotic (Ref: No) & & \\
\hline First Gen & 3.03 & 1.71 \\
\hline Second Gen & 0.93 & 1.13 \\
\hline MHLC & & \\
\hline Internal Locus & 0.23 & $0.11^{\star}$ \\
\hline
\end{tabular}

Note: ${ }^{*} p<0.05,{ }^{* \star} p<0.01,{ }^{* \star \star} p<0.001$ two-tailed test 